\title{
Mechanical Properties and Fracture Behavior of Titanium-Aluminum/Titanium Micro-Laminate Sheet Deposited by EB-PVD
}

\author{
Gu-ping Wang ${ }^{1, *}, \mathrm{Li} \mathrm{Ma}^{2}$ and Meng-xian Zhang ${ }^{1}$ \\ ${ }^{1}$ College of Physics \& Electronic Engineering, Taizhou University, Taizhou 318000, China \\ ${ }^{2}$ College of Mechanical and Electrical Engineering, Guangdong University of Petrochemical Technology, Maoming 525000, China
}

A $110 \mu \mathrm{m}$ thick micro-laminate sheet comprising 14 layers of $\mathrm{TiAl} / \mathrm{Ti}_{3} \mathrm{Al}$ two phase compound and 15 layers of $\mathrm{Ti}$ was prepared by electron beam physical vapor deposition (EB-PVD), and its microstructures and mechanical properties were characterized. Results show that the hardness of interfacial region is about $7.029 \mathrm{GPa}$, higher than that of either component layer. After densification, room-temperature tensile strength and elongation are improved compared to single Ti-Al compound sample, reaching $656.89 \mathrm{MPa}$ and $2.92 \%$, respectively. Its tensile curve presents a distinct jagged feature. High-temperature tensile strength exhibits an abnormal increase with temperature, exceeding $440 \mathrm{MPa}$ at $1023 \mathrm{~K}$. The presence of Ti layers will lead to cracks stagger along the inter-laminar interface or the crack deflection and the micro-bridge connection caused by $\mathrm{Ti}$ layers, due to the $\mathrm{TiAl}-\mathrm{Ti}{ }_{3} \mathrm{Al} / \alpha$-Ti micro-laminate displaying a fine characteristic of delayed fracture. [doi:10.2320/matertrans.M2015176]

(Received May 7, 2015; Accepted August 7, 2015; Published October 25, 2015)

Keywords: electron beam physical vapor deposition, micro laminated sheet, mechanical properties, toughening

\section{Introduction}

TiAl based intermetallic compound, including $\gamma$-TiAl and $\alpha_{2}-\mathrm{Ti}_{3} \mathrm{Al}$, have been investigated extensively as substitutes for nickel-based super-alloys owing to their higher melting temperatures and lower densities, which provide improved specific creep strength for elevated temperature structures materials such as turbine blades, engines and panel of thermal proactive system at temperatures from $770 \mathrm{~K}$ to $1050 \mathrm{~K}^{1-3)}$ However, low temperature brittleness severely restricts their applications. One well-established approach for enhancing fracture resistance is reinforcing TiAl intermetallic compound by inserting modest volume fractions of ductile refractory metals. ${ }^{45)}$ It was proposed originally by Kristic as a means of increasing the energy dissipation (by plastic stretching of ductile materials) in brittle materials. ${ }^{6}$ ) Based on that idea, several multi-layer materials comprised of alternating layers of intermetallic and ductile metal (alloy) such as Ti-6Al-4V/ $\mathrm{TiAl}, \mathrm{Nb} / \mathrm{Nb}_{3} \mathrm{Al}, \mathrm{NiAl} / \mathrm{Ni}, \mathrm{Ni} / \mathrm{Al}$, have been fabricated by different methods like hot packed rolling, hot pressing, solid state diffusion welding technique and so on. ${ }^{7-9)}$ However, there are several limitations for those conventional methods to rapidly prepare free-standing thin sheet with large size $(\delta<0.3 \mathrm{~mm}, \varnothing>1000 \mathrm{~mm})$. In present study, electron beam physical vapor deposition (EB-PVD) technology was used to prepare $\mathrm{TiAl}_{-} \mathrm{Ti}_{3} \mathrm{Al} / \mathrm{Ti}$ micro-laminate foil. EB-PVD is a high-efficiency and non-equilibrium deposition technique. ${ }^{10)}$ It is commonly used to deposit thermal barrier coatings (TBCs) on rotating blades and some high-pressure turbine section vanes, which require surfaces with a smooth finish and the ability to withstand high thermo-mechanical strain. ${ }^{11,12)}$ Recently, a significant amount of research work has been conducted on the application of EB-PVD technology in the production of thin alloy sheets. He et al. investigated the oxide dispersion strengthened (ODS) Nibased super alloy foil with nanocrystalline surface layer produced by EB-PVD. ${ }^{13)} \mathrm{Li}$ et al. studied the isothermal

*Corresponding author, E-mail: gpwang526@sina.com oxidation behaviors of as-deposited and heat-treated $\mathrm{Ni}$ 11.5Cr-4.5Co-0.5Al sheet by EB-PVD at $800^{\circ} \mathrm{C}$. ${ }^{14)}$ The objective of our study was to experimentally investigate the mechanical properties and toughening behavior of TiAl$\mathrm{Ti}_{3} \mathrm{Al} / \mathrm{Ti}$ micro-laminated foil deposited by EB-PVD.

\section{Experimental}

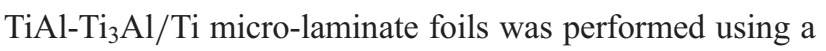
dual source EB-PVD process and the electron beam power was $1.8 \mathrm{~kW}$ with the vacuum level of $1.33 \times 10^{-2} \mathrm{~Pa}$. The pure $\mathrm{Ti}$ and $\mathrm{Ti}-48$ at\% $\mathrm{Al}$ were evaporated and deposited alternately onto a stainless steel round substrate near $1000 \mathrm{~K}$. Following deposition the foils were removed from their substrates and then hot-pressed under $1100^{\circ} \mathrm{C}$ with a pressure of $150 \mathrm{MPa}$ for one hour in argon atmosphere.

The crystal structure of the films was characterized by Xray diffractometer using $\mathrm{Cu} \mathrm{K} \alpha$ radiation and TEM. The cross-section morphology and Fracture surface of selected samples were observed and analyzed by ZEISS OM and Hitachi-S4800 SEM.

For initial evaluation of different component layers, nanoindentation test was performed and the micro hardness and elastic modulus of the samples were obtained by loaddisplacement curves from experimental data processing system. The tensile tests were carried out at $298 \mathrm{~K}, 823 \mathrm{~K}$, $923 \mathrm{~K}$ and $1023 \mathrm{~K}$, respectively. The tensile strain rate at room temperature and high temperature were $0.5 \mathrm{~mm} / \mathrm{min}$ and $1 \mathrm{~mm} / \mathrm{min}$, respectively. Tensile specimens were machined into I-shape with $20 \mathrm{~mm}$ in gauge length and were tested on "Instron Universal Testing Machine".

\section{Results and Discussion}

\subsection{Microstructure and phase}

The cross-sectional SEM observations from Fig. 1 indicate that the foils consisted of 15 layers of $\mathrm{Ti}$ and 14 layers of $\mathrm{TiAl} / \mathrm{Ti}_{3} \mathrm{Al}$ two phase compound, having a total thickness of $110 \mu \mathrm{m}$ and the mean layer thickness ratio was about $1: 1$. 

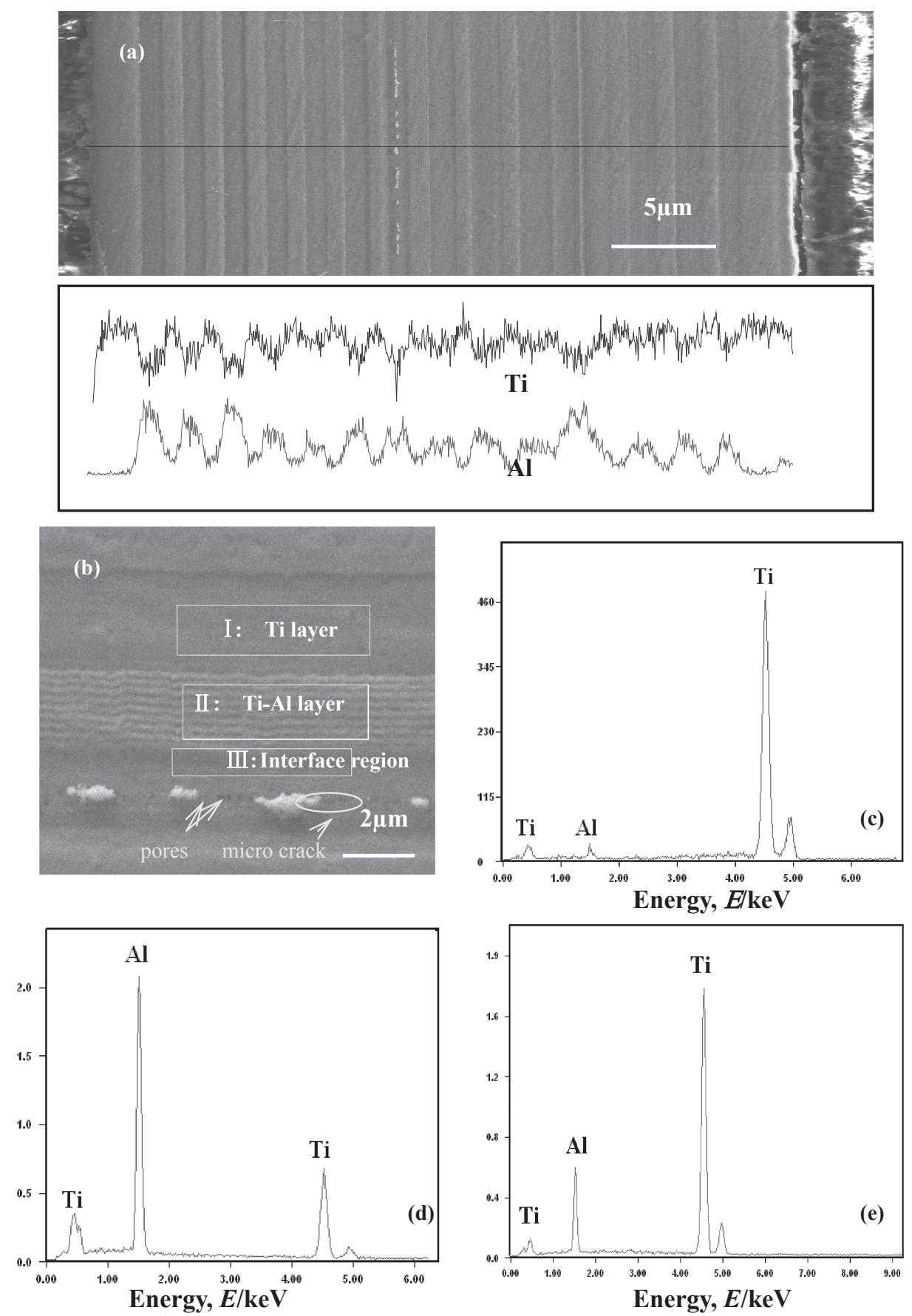

Fig. 1 Microstructure and EDS analysis of TiAl-Ti $3 \mathrm{Al} / \alpha$-Ti micro-laminated deposited sheet; (a) EDS line scan along cross section,

(b) A SEM image of cross section, (c) composition of zone I, (d) composition of zone II, (e) composition of zone III.

Figure 1(b) shows that there are pores and micro cracks in the interface. The EDS line indicated that $\mathrm{Ti}$ and $\mathrm{Al}$ contents present a regular gradient variation along the normal direction of substrate. The EDS plane scanning results show that the percentage composition of Ti layer, TiAl layer and interfacial region are $\mathrm{Ti}-1.16$ at\% $\mathrm{Al}, \mathrm{Ti}-49$ at $\% \mathrm{Al}$ and $\mathrm{Ti}-24.52 \mathrm{at} \% \mathrm{Al}$, respectively. According to the Ti-Al binary phase diagram, constituent of three different zones corresponds to $\alpha$-Ti, $\mathrm{TiAl}+\mathrm{Ti}_{3} \mathrm{Al}$ and $\mathrm{Ti}_{3} \mathrm{Al}$ phase, respectively. Figure 2 shows that there are several sublayers along the cross section of $\mathrm{TiAl}-\mathrm{Ti}_{3} \mathrm{Al}$ layer and form alternating rich-Al zone and richTi zone. Due to different saturated vapor pressure between Ti and $\mathrm{Al}$ elements, $\mathrm{Al}$ atoms will precede $\mathrm{Ti}$ atoms to evaporate and deposit on substrate surface. According to an empirical parameter proposed by Zinsmeister, ${ }^{15}$ ) Ti-Al alloy's ability to fractionate can be characterizes by $\mathrm{K}$ as described with formula (1):

$$
K=\frac{f_{\mathrm{Al}} \cdot P_{\mathrm{Al}}}{f_{\mathrm{Ti}} \cdot P_{\mathrm{Ti}}}\left(\frac{M_{\mathrm{Ti}}}{M_{\mathrm{Al}}}\right)^{1 / 2}
$$

Where $f_{\mathrm{Al}}$ and $f_{\mathrm{Ti}}$ are activity coefficients of components $\mathrm{Al}$ and Ti, respectively; $P_{\mathrm{Al}}$ and $P_{\mathrm{Ti}}$ are their vapor pressures at the liquid alloy evaporation temperature; and $M_{\mathrm{Al}}$ and $M_{\mathrm{Ti}}$ are their molecular masses. It follows that if $K<1$ (when $K=1$, the alloy is being evaporated conformably), Al with a high vapor pressure is evaporated, and then with an increase 


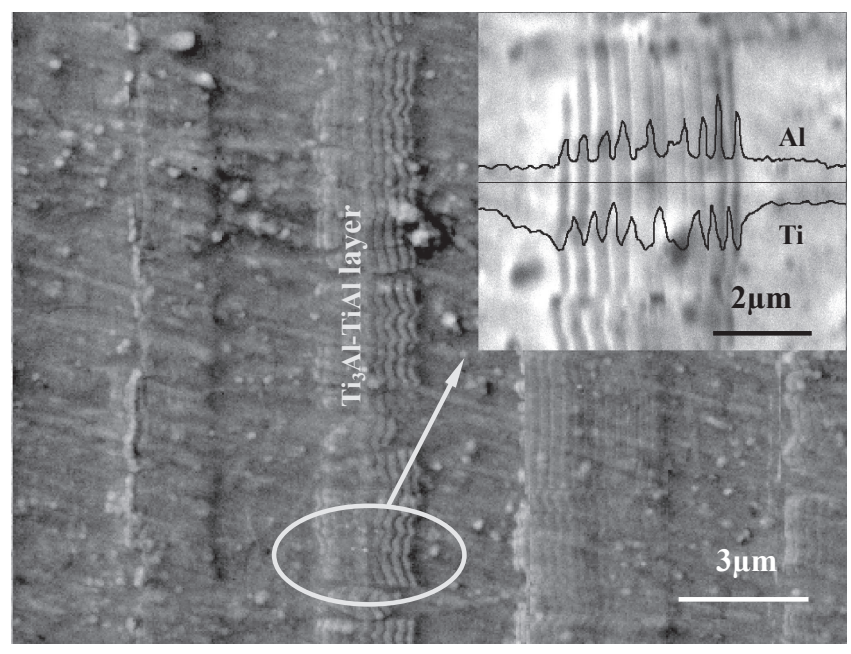

Fig. 2 SEM image of TiAl-Ti ${ }_{3} \mathrm{Al}$ layer and EDS line scan along its cross section.

in the quantity of evaporated alloy, Ti with the low vapor pressure component starts to evaporate. This difference is stronger, the greater that the K parameter derived from eq. (1) and the higher the initial Al concentration is. As a result of the changes mentioned in the vapor phase composition, a concentration gradient is formed across the condensates. Thus, if the evaporating time is enough, the process will transit from the initial non-equilibrium transient state with changing composition into a dynamic equilibrium steady state with stable composition in molten pool, steam and on substrate. Furthermore, according to a mathematical model for the calculation of Ti-Al alloy evaporation and deposition presented by Zeng et al., ${ }^{16)}$ it will take 960 seconds to reach the steady stage when the Ti-48 at\% Al target surface temperature is $2000 \mathrm{~K}$. However, The evaporating and deposition duration for $\mathrm{TiAl} / \mathrm{Ti}_{3} \mathrm{Al}$ layers was about 300 seconds in this work. So, the deposition process of TiAl/ $\mathrm{Ti}_{3} \mathrm{Al}$ layers were always in transient state which leads to continues fluctuation of the composition in molten pool, steam flow and condensate. At the beginning of evaporation, $\mathrm{Al}$ atoms will be evaporated firstly and rich-Al particles in steam flow in the chamber will form rich-Al zone on the condensate' surface. Simultaneously, the Al consumption in the source will lead to rich-Ti on the surface of melting pool, thereupon then the increasing $\mathrm{Ti}$ content in the steam flow will transform from rich-Al to rich-Ti on the condensate. Eventually, several sublayers in the $\mathrm{TiAl} / \mathrm{Ti}_{3} \mathrm{Al}$ component layer formed by periodic variation between rich-Al zone and rich-Ti zone along the depositing direction of $\mathrm{TiAl} / \mathrm{Ti}_{3} \mathrm{Al}$ layer condensate resulted from element content fluctuation of melting pool and steam flow. Based on the thermodynamic calculation presented by Kattner et al., ${ }^{17)} \mathrm{TiAl}_{3}$ phase formed in initial stage of deposition, and along with the deposition process, non-stable $\mathrm{TiAl}_{3}$ phase dissolved into $\mathrm{TiAl}$ phase and $\mathrm{Ti}_{3} \mathrm{Al}$ phase due to $\mathrm{Ti}$ diffusion into $\mathrm{TiAl}_{3}$ phase.

The XRD results as shown in Fig. 3 confirmed that the composites comprised $\alpha-\mathrm{Ti}, \mathrm{Ti}_{3} \mathrm{Al}$ and $\mathrm{TiAl}$ phases, and crystal plane of diffraction peaks was given in the figure. It can be seen from XRD that $\mathrm{Ti}_{3} \mathrm{Al}$ is the dominant phase in intermetallic layer, whereas the characteristic peaks of TiAl present low intensity except higher peak intensity at $38.99^{\circ}$.

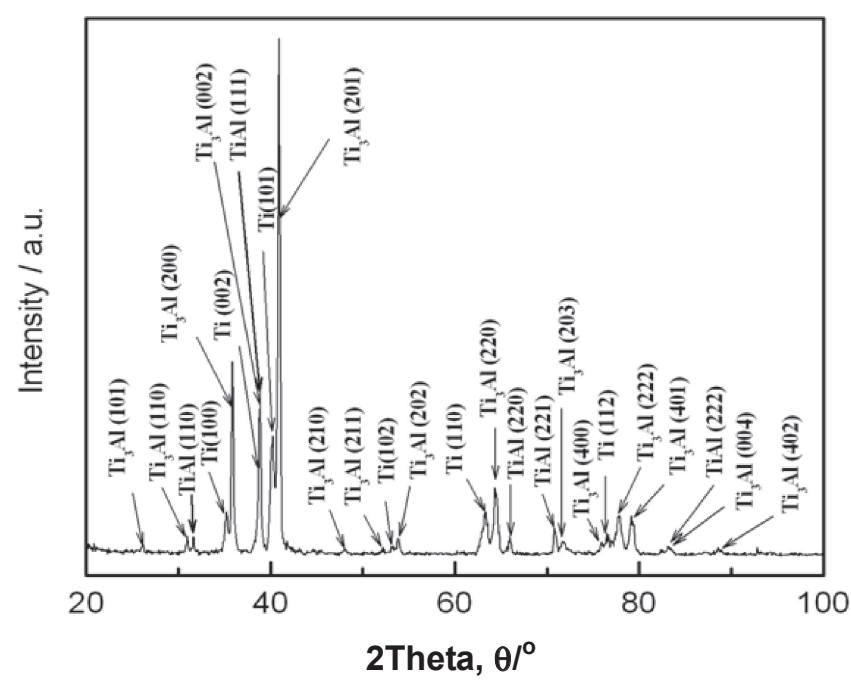

Fig. 3 XRD pattern of $\mathrm{TiAl}_{-} \mathrm{Ti}_{3} \mathrm{Al} / \mathrm{Ti}$ micro-laminate foil.

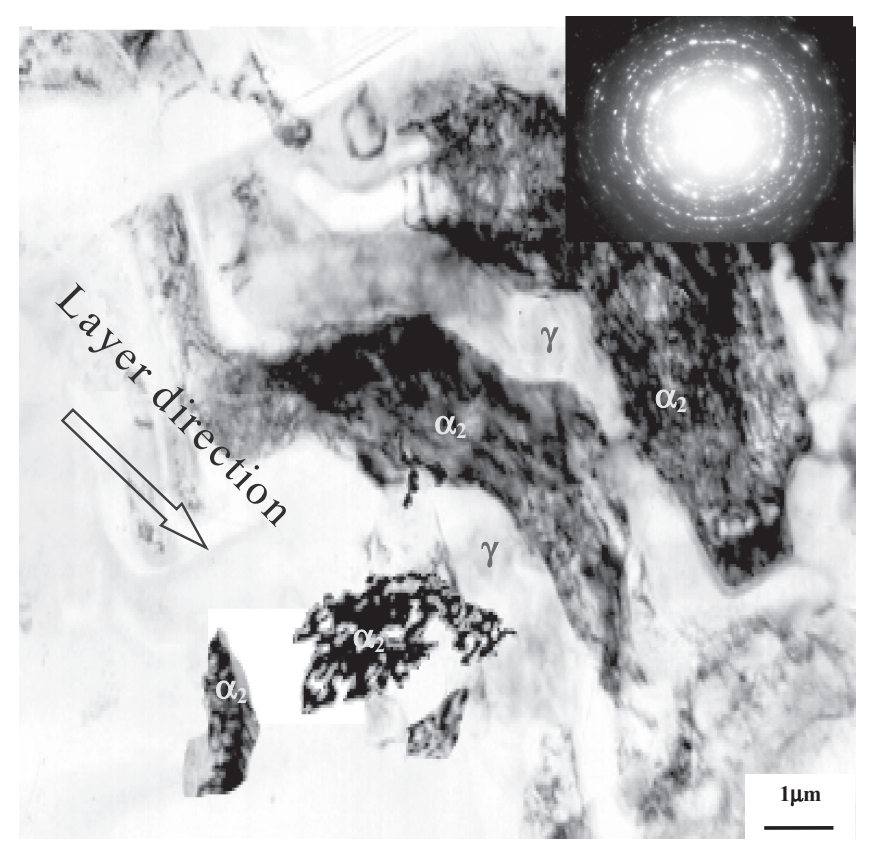

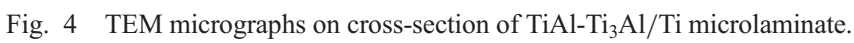

By comparing the EDS and analysis results with phase compositions ranges shown in the Ti-Al binary phase diagram, it was thought that due to the $\mathrm{Al}$ diffusion from intermetallic layer into adjacent $\mathrm{Ti}$ layer, there is a lower content of TiAl phase in intermetallic layer especially at interfacial region.

Figure 4 shows a cross-sectional TEM micrographs and the selected area diffraction (SAED) of the intermetallic layer which confirms the presence of $\mathrm{Ti}_{3} \mathrm{Al}$ phase and $\mathrm{TiAl}$ phase. It can be found that TiAl phase with irregular streaky structure and $\mathrm{Ti}_{3} \mathrm{Al}$ particles were interspersed with non-flat rough interfaces. It is believed that the periodic variation of element content lead to the formation of $\mathrm{Ti}_{3} \mathrm{Al} / \mathrm{TiAl} / \mathrm{Ti}_{3} \mathrm{Al}$ two-phase architecture in intermetallic layers.

\subsection{Mechanical properties}

The load-displacement curve of loading and unloading 


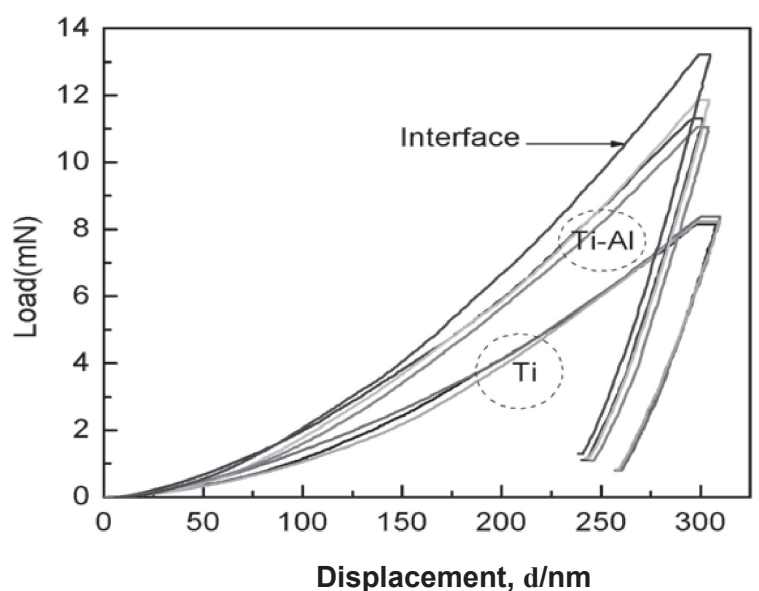

Fig. 5 The load-displacement curve of loading and unloading process of component layer.

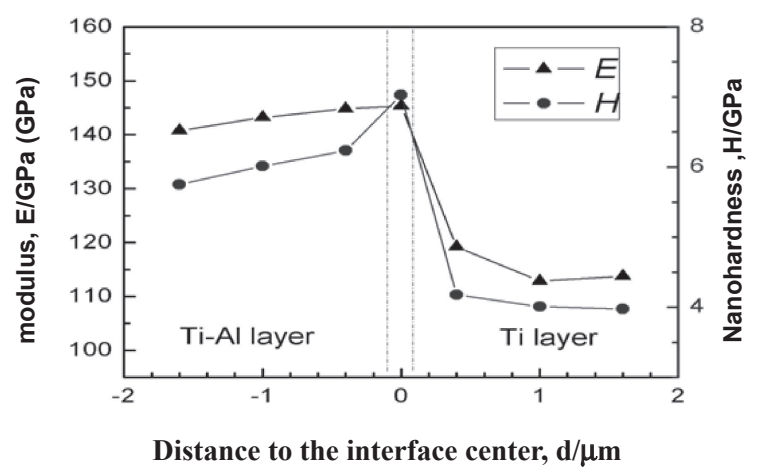

Fig. 6 Hardness and elastic modulus distributions across the cross-section of $\mathrm{TiAl}_{-} \mathrm{Ti}_{3} \mathrm{Al} / \mathrm{Ti}$ microlaminate.

process of component layer obtained with nano-indentation test is shown in Fig. 5. The curves of either component layer or interfacial area are nonlinear and the same component layers have similar mechanical performance. The platform in certain curves indicates that trapping in indenter occurs due to the existence of pore or micro crack in deposited materials as shown in Fig. 1(b). The variation of load value in different zones under same press depth shows that Ti layer can sustain much more plastic deformation than intermetallic layer. Figure 6 shows the status of elastic modulus and nanohardness along the cross section of deposited sample. Elastic modulus of intermetallic layer is close to that of interfacial region with the range of $130-145 \mathrm{GPa}$, similar to that of bulk $\mathrm{Ti}_{3} \mathrm{Al} .{ }^{18)}$ While, elastic modulus of Ti layer is $102-119 \mathrm{GPa}$, lower than that of bulk Ti $(138 \mathrm{GPa}) .{ }^{19)}$ For different locations away from the interface, the elastic modulus fluctuates within a narrow range for both intermetallic and Ti layers due to the component change as a result of diffusion of Al. According to the theory of Koehler, the motion of dislocation in each layer of multi-layered materials will be restricted by the image force owning to different dislocation line energies. ${ }^{20)}$ As a result, multi-layered materials constituted of components with major differential elastic modulus will have a better mechanical performance.

Diffusion of Al element will lead to the gradient decrease of component along adjacent layer. It means that the content

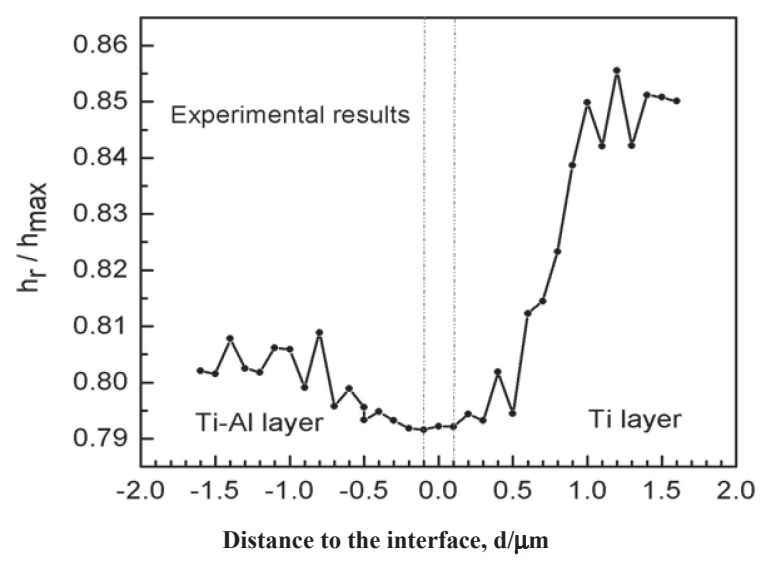

Fig. 7 Plastic deformation capacity distribution at different positions at cross-section in the $\mathrm{TiAl}_{-} \mathrm{Ti}_{3} \mathrm{Al} / \mathrm{Ti}$ microlaminate.

of $\mathrm{Al}$ in interfacial region should be intervenient that of $\mathrm{Ti}$ layer and intermetallic layer. Moreover, the increase of $\mathrm{Al}$ content will help achieve higher hardness, and hence the hardness of intermetallic layer should be higher than that of interfacial region. However, it can be seen from Fig. 6 that nano-hardness reaches to its peak value of $7.029 \mathrm{GPa}$ at the interface region between $\mathrm{Ti}$ and intermetallic layers. While, the gradient variation of hardness of Ti layer is more distinct than that of intermetallic layer. It is considered that there are two reasons for the gradient variation of nano-hardness along the cross-section. Firstly, Ti layer is soft relative to interfacial region so as lead to pile-up effect of which when indenter press in the interfacial region, the closer layer of Ti will pile up. However, the contact area and project area can not be observed directly. It was calculated by load-displacement curve and the value could be higher due to the pile-up effect. Comparatively, intermetallic layer with a higher elastic modulus will form the sink-in effect, it has less effect on measured value. As a result, the exhibited value of hardness and elastic modulus of either Ti layer or interfacial region could be higher than the real value, and that would be more accurate for intermetallic layer. Secondly, the increase of hardness at interfacial region could be related to stress and strain concentration which restricts its plastic deformation. And it can be confirmed in Fig. 7 that plastically deformation behavior take on an opposite trends with nano-hardness and the interfacial region has a very low plastically deformation. Stress and strain concentration at interfacial region restricts its plastic deformation and trend to form crack under low stress.

Table 1 and Fig. 8 show the tensile result of $\mathrm{TiAl} / \mathrm{Ti}_{3} \mathrm{Al} /$ Ti microlaminate foil samples at different temperatures. It can be seen that the stress-strain curve of single TiAl based intermetallic deposited by the same technology exhibit linear elastic, while failure occurs almost without yielding. Correspondingly, the obvious stage of plastic deformation in stress-strain curve of $\mathrm{TiAl} / \mathrm{Ti}_{3} \mathrm{Al} / \mathrm{Ti}$ microlaminate foil indicates the improved property. Multi-stage and multi-stress peak value indicate that there initiates yield hardening during the tensile process. It is a main factor for deposited materials to have a low failure extension ratio that there exists high defect concentration and loose columnar crystals. However, 
Table 1 Tensile test results of hot pressed $\mathrm{TiAl}_{-}-\mathrm{Ti}_{3} \mathrm{Al} / \mathrm{Ti}$ microlaminate foil at different temperature.

\begin{tabular}{cccc}
$\begin{array}{c}\text { Temperature } \\
/ \mathrm{K}\end{array}$ & $\begin{array}{c}\text { Breaking stress } \\
/ \mathrm{MPa}\end{array}$ & $\begin{array}{c}\text { Breaking elongation rate } \\
/ \%\end{array}$ & $\begin{array}{c}\text { Elastic modulus } \\
/ \mathrm{GPa}\end{array}$ \\
\hline 298 & 656.89 & 2.92 & 66 \\
823 & 364.86 & 5.50 & 13.67 \\
923 & 396.43 & 6.49 & 15.08 \\
1023 & 445.91 & 7.08 & 15.06
\end{tabular}

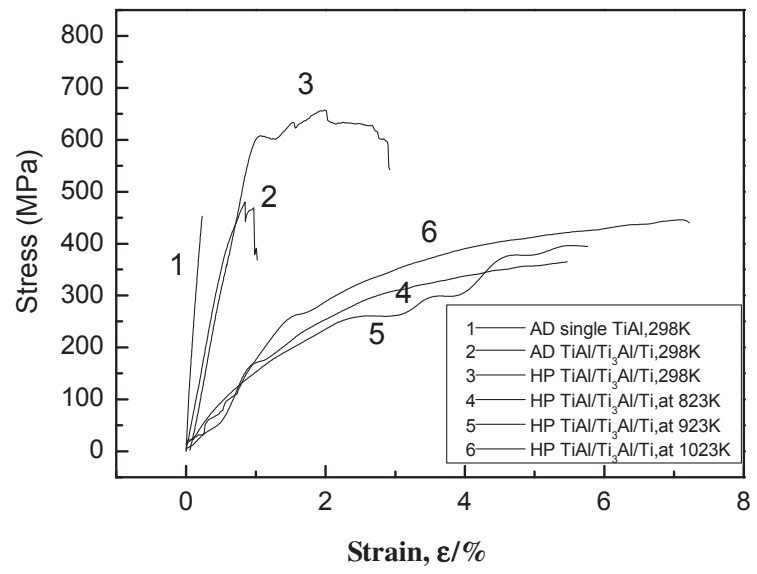

Fig. 8 Tensile stress-strain curves of single Ti-Al and TiAl-Ti ${ }_{3} \mathrm{Al} / \mathrm{Ti}$ microlaminate foil at different temperature.

the tensile curve of hot-pressed sample has a broad stage interval with a gentle variation. Hot-pressed technology can reduce large quantity of micro-pores, which create stress concentration effect and increase crack propagation resisting force by affording more effective loading area. So the breaking strain has been raised for a wide range. And then with temperature increasing, both elastic modulus and yield point increase abnormally. Furthermore, the breaking strength at $1023 \mathrm{~K}$ are even more than that at $823 \mathrm{~K}$. Elongation percentage data implicit micro-laminate foil has better plastic performance due to the Ti contribution. Tensile curves at high temperature have more obvious common specificity of saw-tooth form with many peak points. And slope coefficient of tie line between two adjacent peak points gradually reduces as strain rises. When pure Ti deforms, softened extent led by dynamic recovery recrystallization exceeds strainhardening extent. The abnormal lifting of modulus and strength is definite relevant with Ti-Al intermetallic which has the abnormal temperature characteristic. Kavatata et al. investigated positive temperature dependence of the yield stress in TiAl intermetallic compound at 293 1273 K and concluded that pinning effect caused by dislocation slip at high temperature contribute to this abnormal yield behavior. $^{21)}$

\subsection{Tensile fracture morphology}

The TiAl- $\mathrm{Ti}_{3} \mathrm{Al} / \mathrm{Ti}$ microlaminate foil has special fracture behavior due to its particular microstructure. It is different for the crack propagation mode of micro-laminated foil with that of bulk materials in which the crack would extend along a straight line. For example, as shown in Fig. 9, the crack

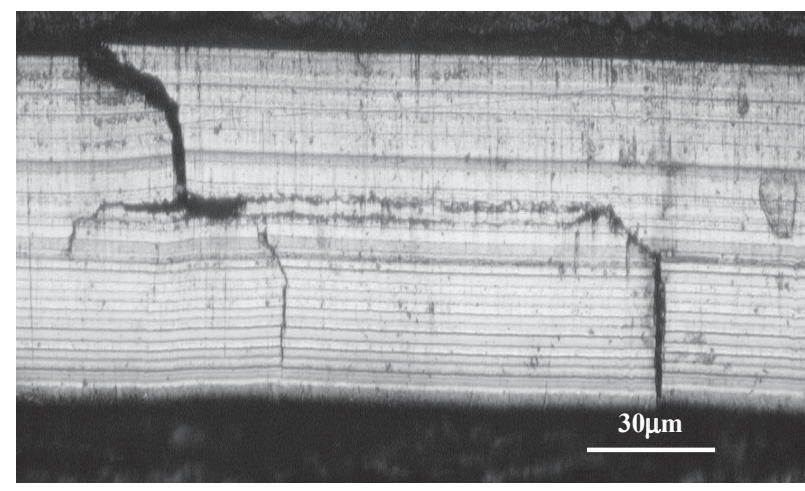

Fig. 9 OM micrographs of tensile fracture surface of hot-pressed TiAl$\mathrm{Ti}_{3} \mathrm{Al} / \mathrm{Ti}$ microlaminate at $298 \mathrm{~K}$.

propagation is not straight across the cross section, but staggering along interface or in layer for many times. After roughly $40 \mu \mathrm{m}$ of crack growth, the macroscopic crack-path morphology shows a single dominant crack with limited branching and Ti layers behind the crack tip, thereby creating a bridging zone in the crack wake. According to material mechanics theory, stress subjected to superficial Ti layer is higher than that of inward Ti layer. So with increasing load, the outermost Ti layer will yield and failure first. During the loading process, crack will extend across laminar interface with high stress that has been indicated through nanoindentation test as above. In the meantime, brittle intermetallic layer will break and form mouth-displacement to be cooperative deformation with Ti layer, and as a result, inner cracks can expand to the core of materials by bridge connection mode. Failure of one or several Ti layers lead to redistribution of stress and stress increase in each layer, residue Ti layer can gradually restore load-supporting through strain-strengthening. When the above process carry on, tensile curve will form an irregular saw-shape till a descending trend lead to final failure as strain-strengthening can not make up for the strength loss by strain strengthening.

A series of SEM micrographs of fracture surface of a TiAl/ $\mathrm{Ti}_{3} \mathrm{Al} / \mathrm{Ti}$ tensile fracture specimen is shown in Fig. 10. The Ti layers appear to be tightly bonded to TiAl layers. The Asdeposited specimen has the clear laminate structure and interlaminar interface. Smooth surface presents brittle rupture trait. Multi-cleavage plane with different height intersected and formed broad cleavage stage as tabbed in $\mathrm{a}, \mathrm{b}$ and c zone as shown in Fig. 10(a). Moreover, d zone presents stream pattern. In fact, those streams are formed by connecting with crack through some certain cleavage stages, and crack origin can be found by stream flow direction. It is shown that downstream direction is vertical to the laminar-interface, so the crack source of TiAl layer lies in the high stress zone of interface. Figure 10(b) exhibits a dissimilar pattern compare to Fig. 10(a). There are both dimples and many cleavage planes on the fracture surface. Dimples come from aggregation of micro-pores. There will form micro-pores under stress in the materials, then those pores grew up and interlink under the effect of slipping. As temperature increases, size and number of dimples increase gradually, and the tensile samples revealed hybrid fracture. Fracture surface at $823 \mathrm{~K}$ as shown in Fig. 10(c) presents obvious 

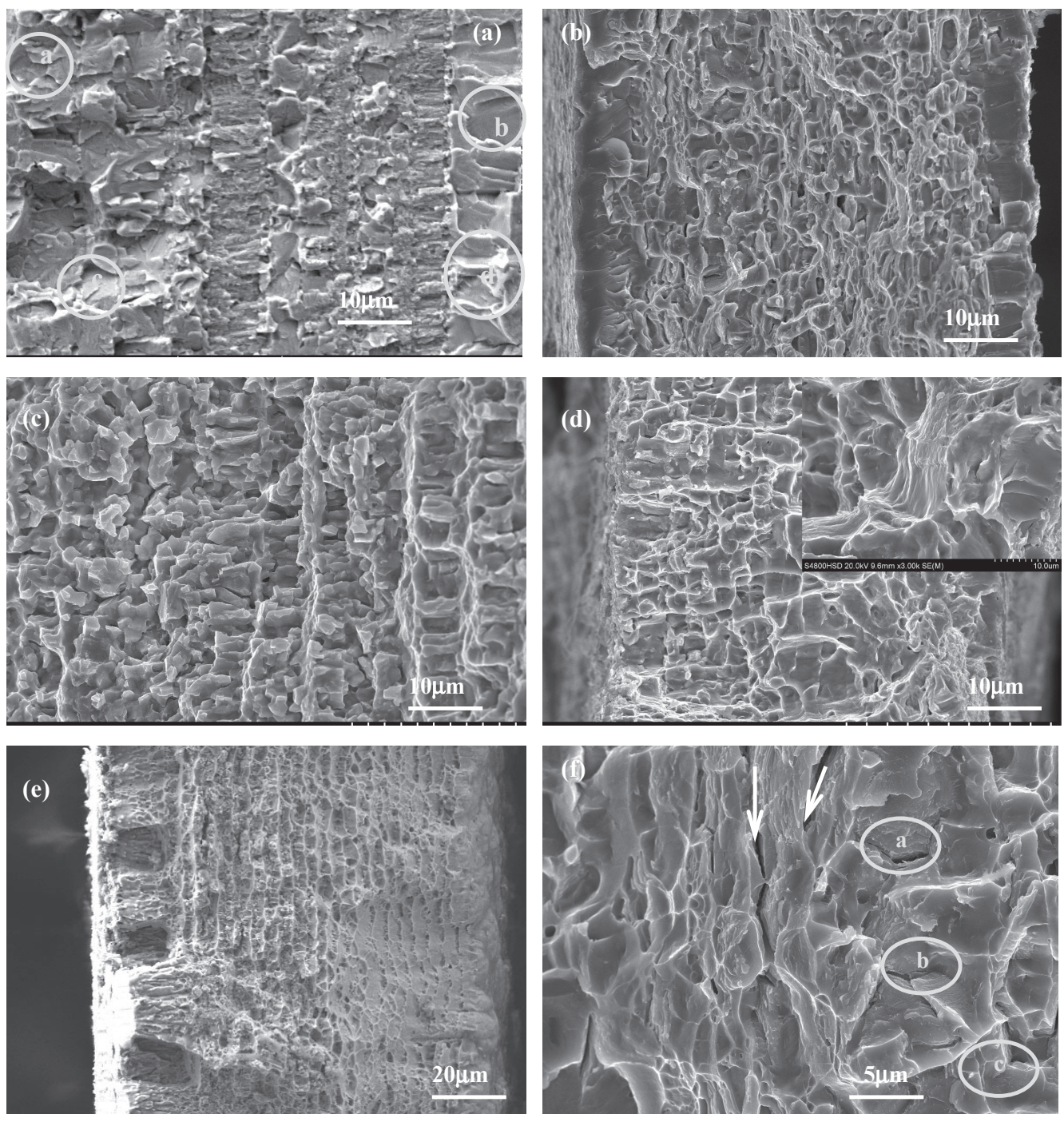

Fig. 10 SEM micrographs of tensile fracture surface of TiAl-Ti $3 \mathrm{Al} / \mathrm{Ti}$ microlaminate at different temperature: (a) as-deposited, $298 \mathrm{~K}$; (b) hot pressed, $298 \mathrm{~K}$; (c) hot pressed, $823 \mathrm{~K}$; (d) hot pressed, $923 \mathrm{~K}$; (e) hot pressed, $1023 \mathrm{~K}$; (f) hot pressed, $298 \mathrm{~K}$. Arrow indicates direction of crack growth.

step-like and roughness pattern accompany with certain necking. Crack expansion proceeds with along interface and through interface alternatively. At $923 \mathrm{~K}$, quantity of dimples and pores increased at meantime and snake sliding and deflection along the grain boundary can be seen from the upper right of Fig. 10(d). Since materials are composed of polycrystalline, crystal grains with different orientations will restrict each other. It is inevitable that slipping proceeds along multiple slip system at high temperature, and finally reflects on snake sliding trait by intersection of slipping system. When it reached $1023 \mathrm{~K}$, dimples spread all over the fracture surface as shown in Fig. 10(e). Abnormal strengthening of TiAl and softening of Ti resulted in lower coordinated deformability, and thus different layer would twist under load. Moreover, it can be seen from left side that several pores leaved over after some columnar crystals were whole pulled out which indicates binding force has been impaired under this temperature.

Metallographic sections of the crack path and scanning electron micrographs of fracture surfaces indicate that the higher toughness in the present TiAl/Ti laminates can be attributed to the effectiveness of Ti layers in promoting crack resistance and resultant crack bridging, cracks will continue for a certain distance along interface and then enter into the next layer as zone of a zone in Fig. 10(f). The deflection of crack can absorb energy to improve fracture toughness property. Besides, it can be seen from Fig. 10(f) that there exist several concurrent zigzag cracks in the mark of $a, b$ and c zones. Those cracks were blocked by Ti layer during the courses of expansion. Some of the Ti layers necked down and the fracture surface exhibited a dimpled appearance, as well as the intergranular fractures, many transgranular cleavage fracture were also observed in the TiAl layers.

\section{Conclusions}

(1) $\mathrm{TiAl} / \mathrm{Ti}_{3} \mathrm{Al} / \mathrm{Ti}$ microlaminate foil comprising 15 layers $\mathrm{Ti}$ and 14 layers $\mathrm{TiAl} / \mathrm{Ti}_{3} \mathrm{Al}$ was deposited using electron beam physical vapor deposition process with a thickness of around $110 \mu \mathrm{m}$. The XRD analysis of the as deposited sample revealed the presence of $\alpha$-Ti, $\mathrm{Ti}_{3} \mathrm{Al}$ phases, and a small amount of TiAl phase. 
(2) Nano-indentation results showed that the nano-hardness from $\mathrm{Ti}$ to intermetallic layers present a gradient distribution. Whereas the elastic modulus were closer in intermetallic layer and interfacial region which was 130-145 GPa and the elastic modulus of $\mathrm{Ti}$ layer was $102-119 \mathrm{GPa}$. The highest values of hardness, $7.029 \mathrm{GPa}$, was observed at interface region between $\mathrm{Ti}$ and intermetallic layer.

(3) Tensile test results showed that addition of Ti layer can increase the room temperature strength and percentage elongation distinctly compared to that of pure $\mathrm{Ti}-\mathrm{Al}$ intermetallic foil. The room temperature tensile strength value and percentage elongation of $\mathrm{TiAl} / \mathrm{Ti}_{3} \mathrm{Al} / \mathrm{Ti}$ microlaminate foil after hot pressing densification process reached $656.89 \mathrm{MPa}$ and $2.92 \%$, respectively. Toughening in $\mathrm{TiAl} / \mathrm{Ti}_{3} \mathrm{Al} / \mathrm{Ti}$ micro-laminate was attributed to the crack deflection and micro-bridge connection caused by the toughening Ti layers which can increase crack propagation resistance.

\section{Acknowledgement}

This work is supported in part by the Public Technology Research Program of Science Technology Department of Zhejiang Province (project No. 2014C37085), and the National Natural Science Foundation of China (Grant No. 51404157). The authors are also grateful for the assistance and advice from Dr. Li Zhang.

\section{REFERENCES}

1) R. Pflumn, S. Friedle and M. Schütze: Intermetallics 56 (2015) 1-14.

2) E. Schwaighofer, H. Clemens, S. Mayer, J. Lindemann, J. Klose, W. Smarsly and V. Güther: Intermetallics 44 (2014) 128-140.

3) M. Goral, L. Swadzba, G. Moskal, G. Jarczyk and J. Aguilar: Intermetallics 19 (2011) 744-747.

4) R. B. Zhang, Y. Y. Zhang, Q. Liu, G. Q. Chen and D. M. Zhang: Mater. Charact. 95 (2014) 157-163.

5) F. T. Kong, Y. Y. Chen and D. L. Zhang: Mater. Des. 32 (2011) 31673172.

6) V. D. Krstic and M. D. Vlajic: Acta Metall. 31 (1983) 139-144.

7) D. R. Bloyer, K. T. Venkateswara Rao and R. O. Ritchie: Mater. Sci. Eng. A 216 (1996) 80-90.

8) H. Y. Kim, D. S. Chung and S. H. Hong: Mater. Sci. Eng. A 396 (2005) 376-384.

9) V. Tsaliris, W. Kappel, G. Alecu, D. Cirstea, L. Leonat and G. Rimbu: SUDURA XXII (2012) 29-38.

10) S. Chen, S. J. Qu, J. Liang and J. C. Han: J. Alloy. Compd. 507 (2010) $146-150$.

11) B. A. Movchan: JOM 48 (1996) 40-45.

12) H. H. Huang, C. C. Diao, C. F. Yang and C. J. Huang: J. Alloy. Compd. 500 (2010) 82-86.

13) X. D. He, Y. Xin, M. W. Li and Y. Sun: J. Alloy. Compd. 467 (2009) 347-350.

14) M. W. Li, G. Zeng and F. He: J. Alloy. Compd. 488 (2009) 30-34.

15) B. A. Movchan and G. S. Marinski: Surf. Coat. Technol. 100-101 (1998) 309-315.

16) G. Zeng, M. W. Li, Q. M. Zhang, J. C. Han and X. D. He: Rare Metal Mat. Eng. 36 (2007) 1759-1762.

17) R. G. Reddy, A. M. Yahya and L. Brewer: J. Alloy. Compd. 321 (2001) 223-227.

18) C. A. Soufen, M. C. de Campos, C. A. F. Pintão and M. Imaizumi: Mater. Sci. Forum 805 (2015) 690-693.

19) W. D. Zhang, Y. Liu, H. Wu, S. Min, T. Y. Zhang, X. D. Lan and T. H. Yao: Mater. Charact. 106 (2015) 302-307.

20) J. S. Koehler: Phys. Rev. B 2 (1970) 547-551.

21) T. Kawabata, T. Kanai and O. Izumi: Acta Metall. 33 (1985) 13551366. 